\title{
The Capacity for Reciprocal Learning Between Law Students and the Community Within Communities of Practice
}

\author{
Paula E. McBride \\ University of Georgia, Athens, USA
}

\begin{abstract}
Adult education is central to creating the conditions for democratic participation. Some people allow themselves to separate from democracy; perhaps they do not see it as directly impacting their daily lives. However, as adults become complacent in both their personal and professional lives, they can fail to notice the roots of oppression spreading. Through both formal and informal education, adults learn how to knowledgeably use tools such as discourse and critical reflection to become more engaged in their communities. One such tool is a community of practice; a safe space of dialogue and communicative action to critically reflect on societal issues. By including law students, future professionals charged with the protection of social justice, communities of practice can form a reciprocal relationship in which students can learn from the community members, and the community can learn from law students. Such deeper learning and engagement can benefit the community with an increased orientation toward social justice.
\end{abstract}

Keywords: communities of practice, legal education, community engagement, adult learning

\section{Introduction}

In today's society, engaged citizens are "tackling public challenges through active citizen involvement in broad partnerships with professionals and officials" (Boyte, 2005, para. 2) where citizens are working together and investing in their community. These citizens can be described as informed, responsible, and conscious of the diversity of needs, political and policy implications, and critically reflecting on society to look beyond the individual (Boland, 2012; Brookfield, 2005). Meanwhile, students exposed to such engagement may have transformative experiences which lead to an individually "deeper understanding and capacity for empathy" where they begin to "question and change the circumstances, conditions, values or beliefs which are at the root of community needs" (Boland, 2012, p. 3). Professional schools, such as law, have the capacity to cultivate deeper learning and social consciousness in intentional spaces, such as communities of practice, between law students and community members (Wenger, 2000).

Adult education is central to creating the conditions for democratic participation. Through both formal and informal education, adults learn how to knowledgeably use tools such as discourse and critical reflection to engage in their communities (Boland, 2013; Brookfield, 2005; Wenger, 2000). Yet, some people allow themselves to separate from democracy, perhaps failing to engage because they fail to perceive it as directly impacting their daily lives (Brookfield, 2005). As adults become complacent in both their personal and professional lives, they can fail to notice how such complacency lays the path for various forms of oppression

Paula E. McBride, MPA, Law School Registrar, School of Law, University of Georgia. 
to grow (Brookfield, 2005). Adults who are continuously engaged help ensure continuance of a democracy serving societal needs (Boland, 2013; Brookfield, 2005).

A reciprocal relationship between law students and community members can benefit all by fostering deliberate conversations, accentuating multiple perspectives, and viewing current political agendas through a critical lens. Using communicative dialogue (Habermas, 1989) as a frame for critical reflection within communities of practice (Wenger, 2000), law students and community members can engage in communicative action to help foster critical learning and reflection (Dewey, 1897; 1916); and, in return, leading to increased social action. This paper presents the idea of communities of practice as a place for engagement (Wenger, 2000) between students and community members where they can participate in deeper learning through the critical discussion and reflection of societal issues. Critical reflection appears a more viable tool for social justice when adults convene in a mutual, respectful communicative space of dialogue (Habermas, 1989; Wenger, 2000). The informal or formal convening of law students in communities of practice with invested citizens would allow for all members to be engaged, increase their knowledge, broaden their perspectives, and critically reflect to better serve the public good (Wenger, 2000). It would be a space for reciprocal learning.

\section{Theorectical Framework}

\section{Communicative Action}

Discourse is intended to be substantial and open, regarding all perspectives with respect to the benefit of others. It is from such discourse that the value commitments, ethics, and morality of society emerge (Habermas, 1989). Communicative action is grounded in a procedural view of rationality (Erikson \& Weigard, 2003; Habermas, 1989). The dominant view of the theory has been depicted as "communication through linguistic utterances (that) may be regarded as "speech acts"” (Erikson \& Weigard, 2003, p. 4). The action of one is dependent upon how that actor interprets and evaluates the speech act of the other whereby focusing on the interpretation rather than the conclusion. The end result is not central; instead it is the manner in which the conclusion is reached. As discussed by Erikson and Weigard (2003), the conclusions are always open to change. If the conclusion is not sufficient, through reflection, critique, and dialogue, it can be changed or adjusted to better meet the need.

Communicative action can be perceived as a process which legitimizes democracy (Erikson \& Weigard, 2003; Habermas, 1989). Democratic legitimacy is established through public dialogue where political questions can be discussed and critiqued (Erikson \& Weigard, 2003). Habermas (1989) referred to this concept of dialogue as the public sphere, explicating this concept emerged in the eighteenth and nineteenth centuries when society became interested in the political questions relevant to them. Political authority was once tasked with the education of the citizenry (Erikson \& Weigard, 2003; Habermas, 1989). Some scholars feel it has evolved into a tool of manipulation where the political sphere no longer retains its critical functionality, now consumed by power-based politics steered by interest groups, money, and political marketing (Erikson \& Weigard, 2003). They have hypothesized "power and strategic interests play the leading part in the coordination of political processes today, not dialogic, communicative action” (Erikson \& Weigard, 2003, p. 8).

Reflexive learning in adult education is a form of learning requiring a person to learn as well as reflect with criticality (Dewey, 1897, 1916; Habermas, 1996). A person immersed in communicative action can become familiar with questioning and challenging; this does not stall dialogue but rather serves to encourage the consideration of different perspectives (Habermas, 1996). Reflexive learning can serve to increase an 
adult's communicative abilities, which is a vital component for the promotion of democracy (Habermas, 1996). Moreover, communicative power is grounded in public discourse (Brookfield, 2005; Erikson \& Weigard, 2003; Habermas, 1989); thereby, granting citizens the ability to control the systems through communicative action (Erikson \& Weigard, 2003; Habermas, 1989). The public sphere allows for safe spaces within civil society to argue and critique the current issues and problems. The better arguments will prevail, and these binding decisions are converted into the law since any law that cannot be rationally debated in the public sphere may be considered illegitimate (Erikson \& Weigard, 2003). This concept can be described as: "human rights facilitate the exercise of popular sovereignty through the institutionalization of communication forms which ensure legitimate legislation by guaranteeing the protection of individual liberty, equality, and participation" (Eriksen \& Weigard, 2003, p. 156).

\section{Communities of Practice}

The idea of the public sphere (Habermas, 1989) as a place of communicative action can be seen in Wenger's (2000) concept of community of practice. The concept of CoP (community of practice) has been advocated as a means of promoting and constructing intellectual capital within a system (in this context, within a community) (O'Donnell, Porter, McGuire, Garavan, Heffernan, \& Cleary, 2003). Communities of practice have been described as a "social fabric of learning" dedicated to the preservation and creation of knowledge (Hara, 2001, p. 2). Within a CoP, members will forgo organizational boundaries and hierarchy to reflect upon and socially construct meaning about an issue or event (O'Donnell et al., 2003; Wenger, 2000). Communities of practice are spaces of dialogue and learning in which members can convene in a safe, neutral environment. These communities engage in an environment of co-inquiry and co-construction of knowledge without the intrusion of authority or hierarchy (Wenger, 2000). Within CoP's, members are bound by a collective understanding of the space, a relationship of mutuality and respect, and a shared language and history (Wenger, 2000). Members of these learning environments benefit from the scholarship of engagement shared social values, and atmosphere of continued learning (Wenger, 2000).

O'Donnell et al. (2003) utilized Habermas' (1989) theory of communicative action to frame their concept of community of practice. The premise is to allow for a communicative space which can bring practical issues into dialogue without influence of power, money, or economic forces (O’Donnell et al., 2009; Wenger, 2000). Groups have the opportunity to focus on issues and needs within their system. The members can engage in critical thinking and reflection, framed by morality and social consciousness, to discuss the best means of solving the problems affecting their community. Intrusion of hierarchy, management, politics and power negatively impact the process (O’Donnell et al., 2003; Wenger, 2000).

Educators can help create "intentional environments" so students and community members can experience "meaningful leadership learning ... comprised of education, experience, and reflection" (Guthrie \& Thompson, 2010 , p. 50). There are five attributes of a community of practice which can be utilized to intentionally create such spaces of learning: (1) group of practitioners; (2) development of a shared meaning; (3) informal networks; (4) supportive culture and trust; and (5) engagement in knowledge building (Hara, 2001). The creation of democratic learning spaces can serve as a means to cultivate the idea of engaged citizenship in both students and adults (Gouthro, 2007). Through a devotion to lifelong learning, adult educators can create such spaces for democratic learning and dialogue which focus on the importance of an active and inclusive citizenship that can foster engagement within education and society (Gouthro, 2007). It has been posited, "lifelong learning is 
linked with developing an active and engaged citizenship, through what many critical theorists term deliberative democracy" (Guthro, 2007, p. 3).

Such an educative space of experiential learning could be achieved with a community of practice which would serve as a bridge between the lifeworld (community) and systems (government and market). Professionals working in the public interest and community members would have the opportunity to participate in dialogue free of the power and politics of the systems. The law students become part of the community of practice, supplementing the dialogue with theorectical views of law, value commitments, and social justice. Each member of the CoP has the potential to add important and different perspectives to the discussion. Current issues can be viewed from the different lens of each actor in a space void of any power and hierarchy (O’Donnell et al., 2003).

The second benefit of the CoP is civic engagement and the legitimization of democracy (O'Donnell et al., 2003; Wenger, 2000). The law students have the opportunity to become engaged in the community through practicing lawyers, community members, and public organizations. The students can learn about the diverse nature of public interest, the clients, various actors, and the community. Through open and reflexive discussion, the students see how all parts of the system function together to best serve the clients and community (O’Donnell et al., 2003; Wenger, 2000). This interaction and discussion allows the students to gain a deeper understanding about the system; an understanding difficult to convey in a classroom setting (Hara, 2001). Moreover, they grow in this knowledge prior to entering the profession; thus, students are better prepared to work with the community and toward social justice upon graduation (Hara, 2001).

\section{Benefits to Law Students}

Professionals, such as lawyers, not only work to serve those in society, but rather create and strengthen the "social networks of meaning and connection in people's lives" (Sullivan, 2013, para. 4). These professionals are in a position of not only providing needed services to the citizenry, but also educating the citizenry about social engagement, civic responsibility, and the meanings and purposes of democracy as they have the opportunity to touch the lives of citizens (Sullivan, 2013). Engagement can be perpetuated not only through formal education but through the informal networks of those working in the community. Professionals have the ability to be moral agents; moreover, the professionals working in public service and the public view are central to the profession's contribution to the social environment and a healthy society (Colby \& Sullivan, 2008; Sullivan, 2013).

Law schools are tasked with creating the conditions for students to broaden their habits of mind while learning how to accommodate the quickly evolving environment in which they will practice (Sullivan, 2013). Students can be taught how to be positively engaged rather than practice with a detached, superior attitude toward the community (Sullivan, 2013). One criticism against legal education is professional training occurs "outside the context of daily practice" (Hara, 2001, p. 2). Sullivan (2013) explained professional students must learn how to relate to clients as "fellow citizens" where they work together to "contribute to particular knowledge" and strive to improve the quality of life for others (para. 7).

Habermas' (1989) idea of the public sphere illustrates a place of engagement for both community members and law students to critically discuss and reflect upon the social issues confronting society. The concept of critical reflection used for social justice seems to be more viable when interested and invested members can convene in a communicative space (Brookfield, 2005; Habermas, 1989). The informal (or formal) 
convening of law students in communities of practice would allow for them to become engaged, increase their knowledge, broaden their perspectives, and critically reflect so they might better serve the public good in their professional lives (Wenger, 2000).

Colby and Sullivan (2008) call for five qualities in professional education that "make for a sustainable, life-long growth in professional competence and commitment" (p. 415). These qualities are: deep engagement; strong professional identity, habits of interpretation, habitual patterns of behavioral response to clients, and the capacity and inclination to contribute to the ethical quality of the profession (Colby \& Sullivan, 2008). Legal education has an established pedagogy which can successfully train law students in legal analysis; however, this strength may no longer have the ability to meet the challenges of our time (Sullivan et al., 2007). Critics of legal education feel law schools need to increase their focus on the reflective, practical, and social justice aspect of lawyering (Colby \& Sullivan, 2008; Sullivan et al., 2007). Using communicative action as a framework (Habermas, 1989), we can create a space of dialogue, such as CoP (Wenger, 2000), which can be supported with social justice and engagement to foster the growth of these qualities in law students.

Membership in learning spaces can assist with the transition from student to professional while strengthening the students' commitment, values, and ideals of professional responsibility (Colby \& Sullivan, 2008). It is not known if forms of CoPs exist within or outside of law schools; however, law schools may be able to utilize this framework and support the conditions needed to encourage their formation or offer support to those already in existence. Communities are continuously evolving, and people must be able to effectively work together, communicate with each other, and respect those who might hold divergent ideals, political affiliations, and religious beliefs (Brookfield, 2005). In addition, through the use of both formal and informal learning, citizens not only gain the ability to knowledgeably participate in democracy, but such engagement, grounded in critical theory and social justice, becomes part of a new social construct that can be passed down to the next generation (Brookfield, 2005). Law students may benefit from learning how to engage in deliberate conversations with community members, viewing each person's perspective, as well as viewing all suggestions and current political agendas through a critical lens.

\section{Benefits to Community Members}

Adults can learn to reflect, discuss, and challenge the current status and political policies (Brookfield, 2005; Dewey, 1897, 1916). The actions of reflection, discussion, and challenge may first appear simple and inherent, but these actions are not to be taken blindly and ignorantly. Adult education is central to creating the conditions for democratic participation (Dewey, 1897; 1916). Through education, both formal and informal, adults learn how to knowledgeably use these tools to engage in their communities (Dewey, 1897; 1916). Reasoned communication and discourse are tools that enable democracy to persevere (Brookfield, 2005). Citizens unable to analytically think, reflect, and revise are open to being misinformed and misled by others, including government leaders, lobbyists, and the media (Brookfield, 2005). Exposure to both informal and formal education can help expand the cognitive abilities of community members so they might develop the capacity to make better informed decisions about political activities and policy (Dewey, 1897; 1916). It is important to continuously expose adults to the civic and political demands of society, and a community of practice can serve as a forum for communicative action (O'Donnell et al., 2003; Wenger, 2000).

Lawyers and law students can contribute to informal adult learning and engagement by conveying social justice issues and explaining the societal consequences (Colby \& Sullivan, 2008; Sarat \& Scheingold, 2004). In 
professional practice, they have the ability and opportunity to impact the community and policy through litigation which can highlight issues of concern while informing both the public and political leaders (Sarat \& Scheingold, 2004).

\section{Contributions to Society as a Whole}

The label of professional has been linked with the ideal of service to the public good, and Colby and Sullivan (2008) depict professionals as having "a commitment to serve the interests of clients and the welfare of society; bodies of specialized knowledge and skill; and procedures through which the professional community provides oversight" (p. 405). One of the end goals of professional education is the "preparation of life-long learners" who should uphold a desire of "continuing, self-directed improvement" (Colby \& Sullivan, 2008 , p. 412). Both the lawyer and public they serve benefit when the professional commits to life-long learning post graduation. One means of fostering the dedication to life-long learning is through social consciousness and engagement with the community (Colby \& Sullivan, 2008).

As law students, they retain their idea of morality and value commitments, but once they enter practice, lawyers must confront the mediums of power, politics, and economic forces (Colby \& Sullivan, 2008). Those in public service are subject to the ideologies of elected leaders, and politics inevitably influence the operation of public organizations. Economic forces are a factor as well, especially within a capitalist environment (Habermas, 1989). Communities of practice between law students and the community can serve as one vehicle to better understanding how to effectively work with others in the community to best serve the needs of society while maneuvering the overarching bureaucratic structure and social inequalities of the system.

Citizens must have the ability to critically reflect while being actively engaged in society, a capacity of deeper learning which can be achieved through either formal or informal education (Dewey, 1897; 1916). Citizens can grow the capacity of reflection on policies and government actions to ensure that all citizens are being considered as well as engage in deliberate dialogue with others. Brookfield (2005) grounds his teaching framework within critical theory, and the use of critical pedagogy linked to scholarship of engagement and social justice can be one approach in which to challenge law students so they might learn to critically reflect rather than assuming the voice of authority is the only truth while stimulating the moral consciousness of the learners. With the creation of a CoP, there is no person with a stronger voice than others. All participants enter the community as co-constructors of knowledge. Each participant has a voice, and all perspectives can be critically discussed and reflected upon in the space. There is a relationship of mutual respect.

Such spaces further encourage the promulgation of social justice and democracy. Habermas (1989) felt that true democracy could only be realized within deliberate democratic discussions between citizens, a process which can help legitimize democracy (Erikson \& Weigard, 2003; Habermas, 1986). There is an atmosphere of collaboration, and as stated by Erikson and Weigard (2003), "Communicative action theory aims to explain or provide an understanding of a wide spectrum of social conditions" (p. 10). Habermas (1989) posits that democracy and change could only be attained through the collaborative speech acts of the citizens operating in the lifeworld. Thus, communicative action can be used as a means of framing social justice, scholarship of engagement, and critical theory in a type of community of practice for law students in hopes such a space will create the conditions to help foster preparedness for engaged citizen lawyers within conventional legal education. 


\section{Implications and Suggestions for Research}

Mentorship and engagement is valued within American legal education, however, there are not established spaces of communicative action between law students and the community members. Each person has an opportunity to learn from each other in such spaces (O'Donnell et al., 2003; Wenger, 2000). Established communities of practice between law schools and their communities can provide deeper learning and critical reflection for all those involved (O’Donnell et al., 2003; Wenger, 2000).

Habermas's (1989) theory holds an opportunity for enhancing legal education. Law students are taught the theorectical principle behind the law. However, while they can analytically dissect a former case, they have neither thoroughly practiced critically reflecting on new issues nor contemplated how these new issues fit into the framework of the law. After being subjected to the socratic method in the first year of legal education, students might need to learn how to re-engage and communicate with rationality and criticality. Also, due to a three-year law curriculum, it is difficult to impart the legal theorectical foundations while also integrating the many new, diverse problems within today's society.

This paper is suggesting research be conducted to first determine if informal communities of practice already exist in which law students and community members engage in communicative dialogue. Such research can inform the field of adult education as well as the specific field of legal education. Additionally, research can add to the concept of communities in practice as applied for reciprocal learning between the community members and professional students who will be joining the community, helping to promote social action. Such research can investigate how adult educators can help support exiting CoPs so deeper learning occurs. Secondly, if such CoPs do not exist, how can adult educators create the conditions where law students and community members craft such spaces of engagement and learning? Further research should be conducted to determine what kinds of CoPs, if any, law students and community members participate in separately, and whether it is plausible to build from existing structures. As the author is writing from the American perspective, it would better inform the literature to include comparative research between law schools and communities on an international level.

\section{Conclusions}

People have always practiced collective learning, and "Participating in these communities of practice is essential to (their) learning. It is at the very core of what makes us human beings capable of meaningful knowing" (Wenger, 2000, p. 229). Communicative action is the way in which citizens can deliberately discuss issues and problems, formulate solutions to benefit the whole, and transfer through laws to the systems (Habermas, 1996; 1989). This form of speech is vital to the moral consciousness of society as it infers critical and reflective dialogue in a safe, neutral, power-free space in which all voices have the ability to be heard and considered (Habermas, 1989). Therefore, communicative action is a theorectical way in which social justice is perpetuated.

Boyte (2005) strongly advocated the use of adult education to revitalize active and participatory democracy. Adults may be inspired to become involved through various channels, such as higher education, community organizations, and community activities (Boyte, 2005), and communities of practice can be the scaffolding for engagement. Engaged citizens and law students can experience a heightened awareness of social issues; in return, they may experience an increased motivation to work for social change (Gouthro, 2007). More 
importantly, engaged lawyers are more apt to continue life-long learning which not only increases professional skills but benefits the citizenry they serve as well (Colby \& Sullivan, 2008). Communities of practice can serve as a bridge between the formal education of law students and the informal education of adults (Hara, 2001). It can be a space for reciprocal learning as well as scaffolding for the conversion of formal knowledge to practical knowledge which can better serve the needs of society (Hara, 2001).

\section{References}

Baxter, H. (2002). System and lifeworld in Habermas's theory of law. Cardozo Law Review, 23(2).

Boland, J. A. (2012). Orientations to civic engagement: Insights into the sustainability of achallenging pedagogy. Studies in Higher Education. DOI:10.1080/03075079.2011.648177.

Boyer, E. (1990). Scholarship reconsidered: Priorities of the professorate. Princeton, N.J.: Princeton University Press.

Boyte, H. C. (2005). Reframing democracy: Governance, civic agency, and politics. Public Administration Review, 65(5). Retrieved online from www.scholarsstrategynetwork.org

Bringle, R. G., Studer, M., Wilson, J., Clayton, P. H., \& Steinberg, K. S. (2011). Designing programs with a purpose: To promote civic engagement for life. Journal of Academic Ethics, 9, 149-164.

Brookfield, S. (2005). The power of critical theory: Liberating adult learning and teaching (1st ed.). San Francisco, C.A.: Jossey-Bass.

Colby, A., \& Sullivan, W. (2008). Formation of professionalism and purpose: Perspectives from the preparation for the professions program. University of St. Thomas Law Journal, 5(2), 404-427.

Dewey, J. (1916). Democracy and education: An introduction to the philosophy of education (1966 ed.). New York, N.Y.: Free Press.

Dewey, J. (1897). My pedagogic creed. New York, N.Y.: E.L. Kellogg Company.

Erikson, E., \& Weigard, J. (2003).UnderstandingHabermas. New York, N.Y.: Continuum Books.

Gouthro, P. (2007). Active and inclusive citizenship for women: Democratic considerations for fostering lifelong education. International Journal of Lifelong Education, 26(2), 143-154. Retrieved online from http://www.tandfonline.com/loi/tled20

Guthrie, K. L., \& Thompson, S. (2010). Creating meaningful environments for leadership education. Journal of Leadership Education, 9(2), 50-57.

Habermas, J. (1989). The theory of communicative action (Volume 2). Boston, M. A.: Beacon Press.

Habermas, J. (1996). Between facts and norms: Contributions to a discourse theory of democracy. Cambridge, M.A.: MIT Press.

Hara, N. (2001). Formal and informal learning: Incorporating communities of practice into professional development. Paper presented at the Annual Meeting of the American Educational Research Association, Seattle, W.A.

O’Donnell, D., Porter, G., McGuire D., Garavan, T., Heffernan, M., \& Cleary P. (2003). Creating intellectual capital: A habermasian community of practice (CoP) introduction. Journal of European Industrial Training, 27(2/3/4), 80-87.

Sarat, A., \& Scheingold, S. (2004). Something to believe in: Politics, professionalism, and cause lawyering. Stanford, C.A: Stanford University Press.

Schön, D. (1983). The reflective practitioner. Basic Books Inc.

Sullivan, W. (2013). Preparing professionals as moral agents. Carnegie Foundation for the Advancement of Teaching. Retrieved from www.carnegiefoundation.org.

Sullivan, W., Colby, A., Wegner, J., Bond, L., \& Shulman, L. (2007). Educating lawyers: Preparation for the profession of law (summary). The Carnegie Foundation for the Advancement of Teaching.

Wenger, E. (2000). Communities of practice and social learning systems. Organization Articles, 2(7), 225-246. 